\title{
UTILIZACIÓN DE ESPECIES NATIVAS DEL "BOSQUE SECO" PARA LA RECUPERACIÓN DEL PAISAJE EN EL PROCESO DE CIERRE DEL BOTADERO A CIELO ABIERTO DEL DISTRITO LAS LOMAS - PIURA
}

\author{
USE OF NATIVE SPECIES OF "DRY FOREST" FOR \\ RECOVERING THE LANDSCAPE IN THE PROCESS OF \\ CLOSING THE DUMP OF THE DISTRICT “LAS LOMAS"- PIURA
}

\author{
Bárbara Elizabeth Montoro Negrón
}

RESUMEN

\begin{abstract}
La investigación se refiere a la fragmentación del paisaje del distrito de Las Lomas en Piura, afectado por la existencia de un botadero a cielo abierto. El estudio se focaliza en la posible restauración del paisaje durante el proceso de clausura. Para lo cual se estudiaron las especies vegetales nativas del bosque seco piurano seleccionando las más resistentes y útiles en el proceso de recuperación, las mismas que fueron colocadas paisajísticamente sobre la cobertura final. Este proceso denominado fito-remediación ayudará a que las raíces de árboles y arbustos estabilicen el área clausurada, degraden los residuos y absorban los lixiviados. Una correcta colocación y posterior crecimiento de la vegetación recuperará el paisaje, ayudará al retorno de la fauna desplazada y permitirá que se acelere este proceso regenerador para el bienestar de la población vecina.
\end{abstract}

Palabras clave.- Botaderos a cielo abierto, Paisaje fragmentado, Fitorremediación.

\begin{abstract}
The investigation concerns landscape fragmentation district of Las Lomas in Piura, affected by the existence of an open dump. The study focuses on the possible restoration of the landscape during the decommissioning process. To which we studied the native plant species of dry forest piurano selecting the most resistant and helpful in the recovery process, the same that were placed scenically on the final cover. This process called phytoremediation help the roots of trees and shrubs stabilize the closed area, degrade and absorb waste leachate. Proper placement and subsequent vegetation growth recover the landscape will help the return of displaced wildlife and allow this process to accelerate regenerator for the welfare of the surrounding population.
\end{abstract}

Keywords.- Open dumps, Fragmented landscapes, Phytoremediation.

\section{INTRODUCCIÓN}

La restauración del ecosistemay el paisaje que lo compone,al concluir el proceso de clausura del botadero a cielo abierto en Las Lomas, Piura,requirió utilizar herramientas de la Ecología del Paisaje ${ }^{[1-5]}$, de la Gestión Ambiental ${ }^{[6-10]}$ y de las ciencias biológicas ${ }^{[3,11-15]}$. La ecología del paisaje permitió el análisis de la fragmentación del paisaje natural como consecuencia de la existencia de este uso contaminante; se evaluaron las posibilidades de recuperación a un corto o mediano plazo.

Msc. Arq., docente de la Facultad de Arquitectura Urbanismo y Artes, Facultad de Ingeniería Ambiental Universidad Nacional de Ingeniería. 
Las técnicas de clausura de la gestión ambiental se adaptaron a las condiciones particulares de limitación de recursos y materiales específicos de esta experiencia; y la investigación biológica contribuyó con técnicas de fitorremediación con la utilización de las especies vegetales nativas encontradas sobre el botadero, arbóreas, arbustivas y las de cobertura natural como componentes del paisaje piurano. Esta experiencia fue la etapa final del proyecto de clausura del botadero por parte de la Municipalidad de Las Lomas y de la Asociación Benéfica PRISMA como ejecutor de las obras civiles.

La necesidad -y desafío- de encontrar nuevas formas de recuperación ambiental y paisajista a bajo costo, requirió que no se siguieran las pautas técnicas estándares, es decir no se impermeabilizó previamente el suelo receptor ni se colocó un geo textil sobre los desechos, se utilizó como cobertura la tierra extraída de la excavación del nuevo relleno sanitario; además porque las extensiones de plazos administrativos no previstos incidieron negativamente sobre el presupuesto inicial.

El distrito de Las Lomas, está ubicado a dos horas de la ciudad de Piura, forma parte del ecosistema de "Bosque Seco muy ralo de lomadas y colinas", propio del norte del Perú, el bosque está en peligro de extinción por el avance de la agricultura y de la extracción de leña, así como por la contaminación de la minería informal. El distrito Las Lomas está comprendido dentro de dos zonas de vida, bosque seco ralo de lomadas bsr-l y bosque seco ralo de colinas bsr-c (INRENA 1994 ${ }^{[16]}$, denominado también bosque estacionalmente seco (Linares, La Torre 2008) ${ }^{[17]}$, que proporciona un paisaje característico y único a esta zona geográfica.

\section{RESTAURACIÓN DEL PAISAJE EN LA ZONA CLAUSURADA DEL BOTADERO LAS LOMAS}

El paisaje del área de bosque seco alrededor de la zona del botadero municipal del distrito Las Lomas, fue documentado cuantitativa y fotográficamente para esta investigación durante un periodo de once meses, aproximadamente un ciclo biológico anual; utilizando dos escalas de análisis, en primer lugar escala de macro paisaje para medir la fragmentación sufrida sobre el mosaico paisajista del bosque seco circundante a la zona del botadero, realizada en un área de 61,247 ha aproximadamente, que abarcó el bosque seco circundante al centro poblado Las Lomas.

En segundo lugar, se consideró la micro escala a nivel del observador, con un radio de $10 \mathrm{~m}$ alrededor del botadero, correspondiendo a 1.05 ha del área a restaurar en el botadero y sus alrededores. Se observó la existencia de la vegetación predominante en sus alrededores, localizándola en planos, identificando, clasificando y fotografiando árboles y arbustos.

Se encontró y señaló algunos árboles y herbáceas que crecían sobre los residuos, las que tenían una buena adaptación a la descomposición propia de este botadero, a las posibles emanaciones de gases y a la quema informal de residuos. En la recuperación del paisaje propuesta, la vegetación existente se complementaría instalando otras variedades nativas del bosque seco.

Se debe señalar que el ecosistema de bosque seco del distrito Las Lomas es muy frágil, su equilibrio y preservación depende del ciclo climático del Fenómeno del Niño óENSO ${ }^{[18]}$. Desde hace varios años el bosque seco viene siendo afectado por la actividad agrícola, la eliminación del Algarrobo Prosopispallida y por la expansión de las áreas urbanas -con el uso de botaderos de basura- y últimamente por las actividades de minería informal. Acciones que han dado lugar a la fragmentación del ecosistema y de su paisaje.

Con respecto a la disposición final de residuos sólidos, en Las Lomas no se tiene ningún tipo de control sanitario, se ha confiado la degradación de los residuos a la Naturaleza, a la erosión natural, a la lluvia, al río o dejando que pequeños mamíferos, las aves, los roedores e insectos hagan la tarea de eliminar los residuos orgánicos y la carroña.

Por su localización, el botadero degrada el paisaje y afecta el ecosistema natural; la segregación de subproductos de la basura promueve la proliferación de negocios relacionados con la reventa de materiales y el comercio ilegal; ello ocasiona la depreciación de las áreas, genera suciedad que se expande por el viento afectando un área mayor del bosque, incrementando la contaminación atmosférica y la falta de seguridad 
por el tipo de personas que concurren a estos sitios.

La restauración de este paisaje incidió en una visión holística del hecho; donde la identificación de la distribución espacial de la vegetación arbórea, de la fragmentación del paisaje natural del bosque seco constituyeron una primera etapa que dieron como resultado la estimación del área afectada por el botadero, sus límites y el impacto de la recuperación de las unidades paisajistas fragmentadas.

\section{MATERIALES}

Se utilizó cartografía a diferentes escalas $(1: 25,000 ; 1: 50,000)$, en mapas fuente del IGN (Instituto Geográfico Nacional) en dos dimensiones ortogonales y fotografías satélite de Google. Se hizo un relevamiento de los árboles existentes utilizando el Sistema de Posicionamiento Global Satelital (GPS por sus siglas en inglés).

Se tomaron fotografías mensuales de los cambios estacionales del paisaje, indicando como referencia los hitos naturales. Se hizo un registro fotográfico de la vegetación arbórea, arbustiva y herbácea de los alrededores del botadero.

Se utilizó el levantamiento topográfico realizado por la Asociación Benéfica PRISMA para el trazado y medición de la vegetación existente en el interior del botadero.

Se utilizó el programa AutoCad@ para el vertido de las imágenes y del relevamiento de la vegetación arbórea sobre el levantamiento topográfico y el posterior cruce de las variables.

Las imágenes finales que simulan la restauración del paisaje del botadero se trabajaron con el Programa Photoshop@ editor.

La cobertura de tierra cultivable instalada sobre el botadero estaba constituida por el suelo cultivable reservada para este fin, de la excavación del nuevo relleno sanitario ubicado a $800 \mathrm{~m}$ de distancia, la cobertura final tiene un espesor aproximado de $60 \mathrm{~cm}$. Se tomaron muestras de la tierra del relleno sanitario a ser utilizada como cobertura de cierre del botadero; recogidas a dos niveles, a $1.5 \mathrm{~m}$ de profundidad para conocer sus características de permeabilidad y a $25 \mathrm{~cm}$ de profundidad para conocer sus características de $\mathrm{pH}$ y del suelo cultivable, esa capa es la que recibió a la vegetación sobre el área clausurada del botadero. La permeabilidad encontrada fue de 3.20 E-0.5.

La vegetación que se instaló estuvo compuesta de árboles y arbustos nativos y/o naturalizados, esta vegetación fue cultivada expresamente para la investigación en la ciudad de Piura.

Tabla $N^{\circ} 1$ Vegetación para restauración.

\begin{tabular}{|c|c|}
\hline Vegetación & $\begin{array}{l}\text { Trabajo } \\
\text { campo }\end{array}$ \\
\hline Árboles & $\begin{array}{l}\text { unidades } \\
\text { instaladas }\end{array}$ \\
\hline $\begin{array}{l}\text { Faique }- \text { Acacia } \\
\text { macracantha }\end{array}$ & $7 \mathrm{u}$ \\
\hline $\begin{array}{ll}\text { Palo verde } & - \\
\text { Cercidiumpraecox } & \end{array}$ & $5 \mathrm{u}$ \\
\hline $\begin{array}{l}\text { Eritrina } \\
\text { Erythrinasmithiana }\end{array}$ & $5 \mathrm{u}$ \\
\hline $\begin{array}{l}\text { Palo } \quad \text { santo } \\
\text { Burseragraveolens }\end{array}$ & $3 \mathrm{u}$ \\
\hline $\begin{array}{l}\text { Charán } \\
\text { Caesalpineapaipai }\end{array}$ & $4 \mathrm{u}$ \\
\hline $\begin{array}{l}\text { Parkinsonia } \\
\text { Parkinsoniaaculeata }\end{array}$ & $3 \mathrm{u}$ \\
\hline $\begin{array}{l}\text { Arabisco } \\
\text { Leucaenaleucocephala }\end{array}$ & $4 \mathrm{u}$ \\
\hline Arbustos & $\begin{array}{l}\text { unidades } \\
\text { instaladas }\end{array}$ \\
\hline Overo - Cordialutea & $4 \mathrm{u}$ \\
\hline $\begin{array}{l}\text { Bellaquillo }- \text { Thevetia } \\
\text { peruviana }\end{array}$ & $35 \mathrm{u}$ \\
\hline Buganvilia - & \\
\hline Bougainvillea peruviana & $8 \mathrm{u}$ \\
\hline
\end{tabular}

Para el riego por goteo se utilizaron "microreservorios" diseñados por el Ing. Mario Matorel éstos están compuestos de 4 botellas recicladas de 31 de capacidad cada una, unidas por un catéter, este sistema de "microrreservorios" se instala al lado de cada planta y son llenados de agua una vez al mes. Como sistema de protección contra el viento se colocaron tutores de caña y contra los animales que se alimentan de los brotes tiernos de la vegetación se utilizaron botellas recicladas de 
tres litros, las que se pusieron como un cilindro protector.

\section{MÉTODOS}

La primera etapa fue de evaluación paisajista de la Unidad Paisajista Matriz, cuyo Geosistema serviría de línea base para la recuperación de los efectos de la fragmentación en el bosque seco, dados por el botadero.

Los mapas temáticos se superpusieron con el fin de integrar estos atributos del Geosistema de Las Lomas y su macro paisaje. Como primer paso utilizando las técnicas de análisis y evaluación de los patrones espaciales de Long, citados por Olff ${ }^{[50]}$, se identificó la Unidad Paisajista definiendo su estructura y las características de homogeneidad en un área de 61,247 ha del ámbito de las Lomas. La UP se obtuvo con el cruce de los mapas temáticos de topografía, pluviometría, evapotranspiración, vegetación estacional del bosque seco, de temperaturas, de áreas susceptibles a la erosión, de usos del suelo y mapas de cultivos, la información de estas variables procedió de fuentes oficiales (SENAMHI, INGEMMET, CIPCA, entre otras).

Con la superposición de los mapas temáticos se obtuvieron varias unidades paisajistas menores, las que se delimitaron gráficamente y de las cuales se escogió la Unidad Paisajista que contiene la zona del botadero. Esta unidad fue identificada como la Unidad Paisajista Matriz (UPM) y base para los análisis y propuestas posteriores. En el gráfico se observan varias macro zonas ó unidades paisajistas.

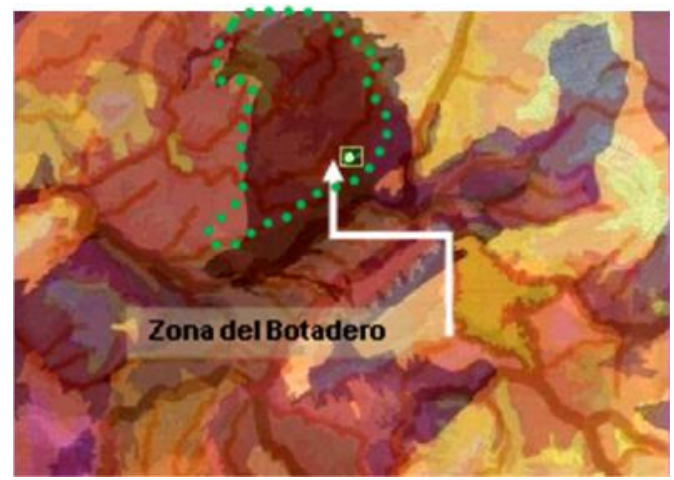

Fig. 1 Mapa síntesis de la Geomorfología del bosque seco de Las Lomas, Piura. Elaboración propia.
En la UPM se señalaron como línea base los patrones obtenidos de geomorfología, altimetría, suelo, temperatura, precipitación y cúmulos de vegetación, que caracterizan el paisaje natural de esta zona.

La cantidad y distribución espacial de los árboles fueron obtenidos en la fotografía aérea del Servicio Aerofotográfico Nacional del año 1990 y en la imagen satelital Google del año 2007, precisando esta información con el relevamiento en campo de los árboles y los arbustos realizado con un GPS el mes de julio del año 2010. Esta información primaria fue contrastada con la información del Proyecto Algarrobo (INRENA 1997) ${ }^{[19]}$ sobre el tipo de árboles y su densidad en el Bosque Seco.

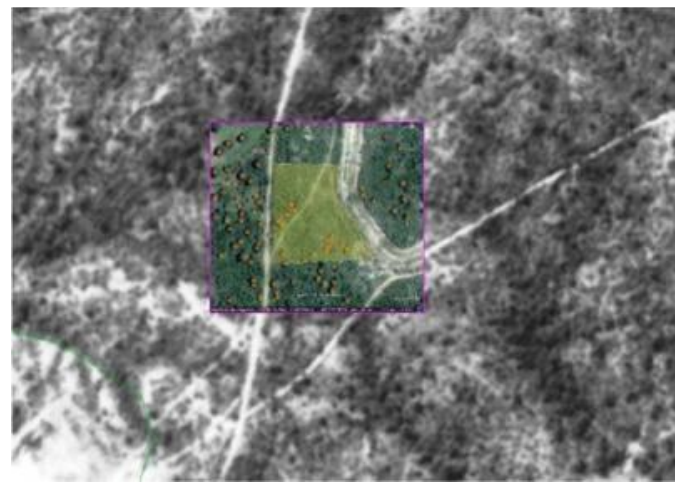

Fig. 2 Foto aérea del IGN con superposición de foto satelital Google y trazado del botadero por Ing. Pedro Pingo superposición B. Montoro.

La UPM a su vez no se presentaba intacta, los materiales ecológicos y sus procesos claramente estaban interrumpidos por la existencia del botadero, de los caminos que conducen a éste, de un canal de desfogue de aguas de escorrentía, por campos agrícolas y por otras pequeñas construcciones.

Utilizando el método gráfico de Forman y Wenche ${ }^{[20]}$, sobre la UPM se evaluó con mayor detalle la fragmentación del bosque seco en un área de $82.5 \mathrm{ha}$, sobre la cual se identificaron los parches en el paisaje, determinándose su número, tamaño medio, su forma y distribución, así como el perímetro y la cantidad de bordes entre ellos. Distinguiéndose el nivel de alteración del paisaje como "salpicado o jaspeado". 


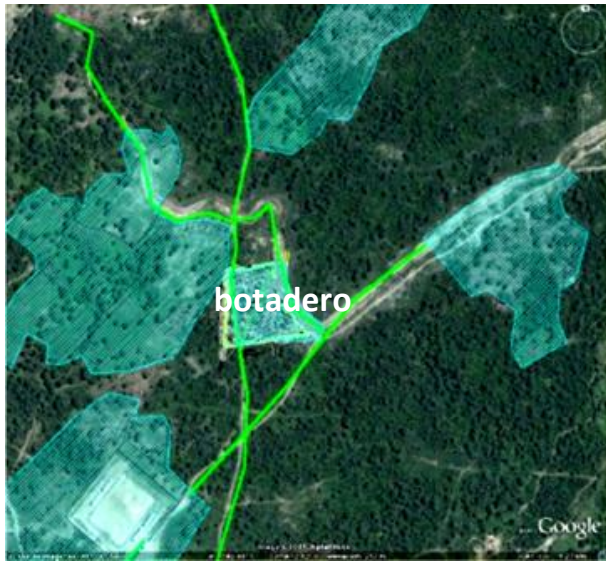

Fig. 3 Fragmentación del bosque seco en la zona botadero Las Lomas.

En segundo lugar, el diseño de las redes de restauración ecológica, de los sistemas de control de aguas superficiales y de drenaje, de la cobertura vegetal final y el posible control de los asentamientos. Para lo cual se estudió la conectividad entre los parches mediante el análisis de los corredores, su número y la forma de sus cruces, así como la conformación de las posibles redes de restauración ecológica y paisajista.

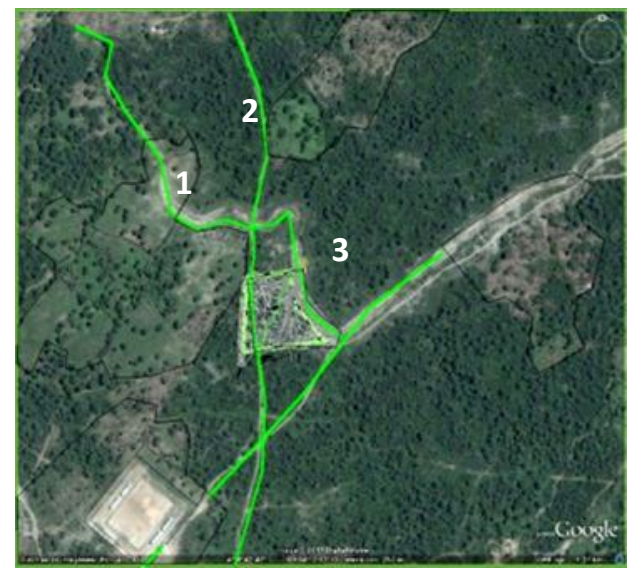

Fig. 4 Corredores cercanos al botadero Las Lomas.

En gabinete se analizó el volumen y las características de los residuos depositados en el botadero, definiendo las formas y volúmenes finales a depositar en el área.

El volumen de residuos recogidos es de 494.49 $\mathrm{tm} / \mathrm{mes}$ por lo que se estimó unas 4,747 tm en los 3 años de operación del botadero.
El botadero clausurado se encontrará sometido a los efectos del clima, resultando imprescindible la ejecución de un buen sistema de drenaje de aguas superficiales para lo cual debe instalarse una red de evacuación rápida a base de zanjas de grava, Jaramillo $^{[21]}$, a las que evacuará el agua de escorrentía de la cubierta del relleno.

Las zanjas o canales se realizan excavando en el suelo natural una zanja perimetral a lo largo de todo el botadero, y utilizando el material gravoso y canto rodado para ayudar a direccionar el flujo de agua.

En gabinete se trazó la zona con la topografía final del área de cierre considerando las redes existentes y los volúmenes de los residuos. Se dibujaron los árboles eliminados en su antigua ubicación y los árboles relevados en campo en un radio de $10 \mathrm{~m}$ alrededor del botadero, también se consideraron los árboles en crecimiento al interior del botadero, entre los residuos.

Se estudió la distribución espacial de los árboles, trazándose las redes de corredores que conectasen los parches encontrados, todo con el objetivo de restablecer los flujos (de materia y energía) que hubieran sido interrumpidos por el uso como botadero. El diseño de estas redes contempló tener un número máximo de cruces entre los corredores.

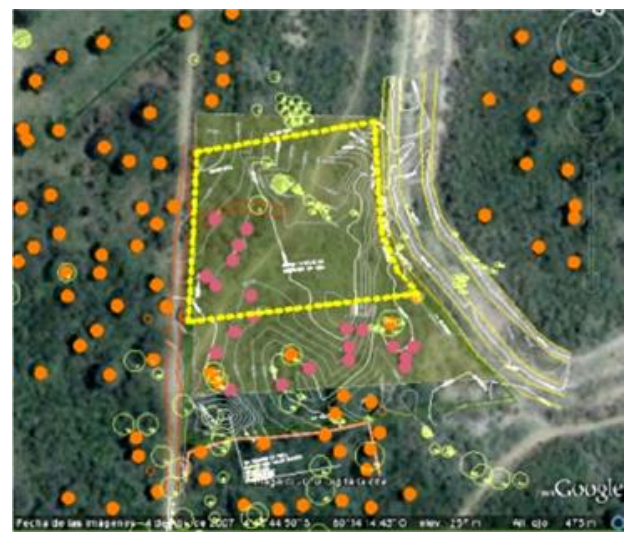

Fig.5 Área del Botadero Las Lomas 1.05 ha, y área para el Proyecto Piloto en líneas segmentadas color amarillo.

La cobertura final se hizo con una capa impermeabilizante de tierra areno-arcillosa de 45 $\mathrm{cm}$ y posteriormente una capa de $60 \mathrm{~cm}$ de profundidad con la tierra vegetal de la excavación 
del relleno sanitario. Se modelaron lomas para evitar el ingreso de lluvia, cuyos bordes son las zanjas de coronación rellenas de grava y tierra vegetal. Por la forma de organización y dimensiones de los montículos de residuos, se calculó que la altura máxima de las lomas debería ser de $60 \mathrm{~cm}$.

Se seleccionó la vegetación nativa más apropiada para los objetivos de remediación del botadero, los árboles de raíces profundas para la absorción de lixiviados en napa profunda y los árboles de raíces extendidas para que estabilicen los residuos.

Los arbustos de follaje medianamente tupido para que sirvan de barrera de protección contra le erosión del viento y evitar la dispersión de la capa de tierra vegetal.

La vegetación mencionada se instaló en las zanjas de coronación con la finalidad de que absorban la escorrentía y pudieran tejer sus raíces hacia los residuos, estas zanjas cumplen la función adicional de red de restauración ecológica.

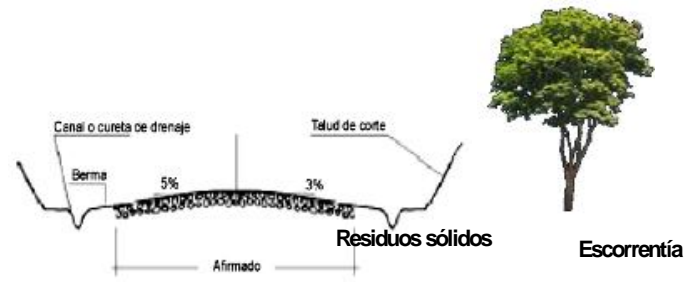

Fig. 6 Corte que muestra las lomas, el canal de drenaje y el crecimiento de la vegetación.

En la superficie de las lomas crecerán las herbáceas nativas espontáneamente de las semillas existentes en la tierra de cobertura utilizada.

Las plántulas instaladas estarán protegidas por un sistema de soporte con cañas y con un cilindro alrededor para evitar se doblen por el viento y crezcan erguidas y para que las lagartijas no se las coman hasta que crezcan y adquieran su propia resistencia.

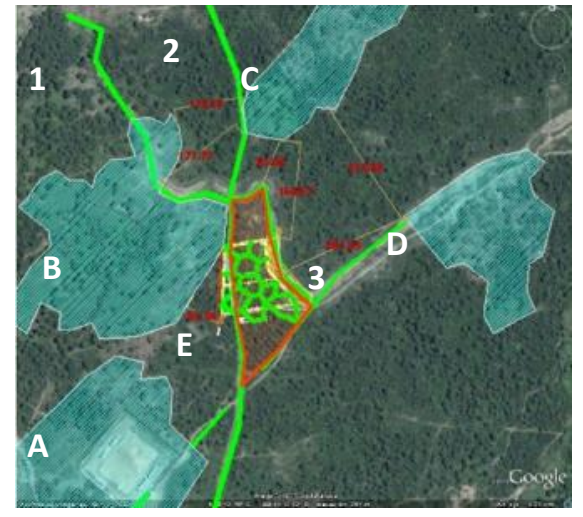

Fig. 7 Tejido permeable sobre el botadero que restaurará el paisaje de la Matriz del bosque seco.

El sistema inicial de riego por goteo con micro reservorios está colocado en cada arbolito y arbusto plantado. Este sistema se mantendrá activo hasta la temporada de lluvia, luego los procesos naturales de las plantas y el clima se deberán hacer cargo.

\section{ESPECIES VEGETALES PARA LA RECUPERACIÓN ECOLÓGICA Y PAISAJISTA}

La restauración ecológica del paisaje de Las Lomas implicó devolver a sus ubicaciones originales, los árboles y arbustos que hubieran sido eliminados por efectos del botadero. Para este caso, primero se realizó la búsqueda bibliográfica de especies nativas y naturalizadas en la zona. Como segunda etapa, se consultó la investigación de especialistas que evaluaron el tipo de vegetación existente en esta zona del bosque seco, sus características y densidad. Una tercera etapa fue explorar con el apoyo de los especialistas en el bosque seco, la posibilidad de una recuperación a corto plazo de la zona con otras especies nativas del bosque seco, buscando que la flora disponible en Piura ó Las Lomas pudiera proporcionarnos el servicio de restauración deseado.

La bibliografía histórica sobre el bosque seco nos remitió a Weberbauer y Ferreyra ${ }^{[12,15]}$ ambos autores reportaron las principales especies de árboles y arbustos del Bosque seco". La información actual está basada en el levantamiento de la vegetación en los alrededores 
del Botadero realizada por el Ing. Agro. Nelson Aguilar personal especialista de la AB PRISMA.

Con respecto a la aplicación para la remediación ambiental de la zona de clausura del botadero, las plantas consideradas valiosas para la restauración deberían presentar las siguientes cualidades:

1. Ser de fácil propagación.

2. Resistir condiciones limitantes como, baja fertilidad, sequía, suelos compactados, de $\mathrm{pH}$ alto o bajo, salinidad.

3. Tener un crecimiento rápido y buena producción de materia orgánica como hojarasca, de preferencia con una relación alta de $\mathrm{C} / \mathrm{N}$.

4. Tener alguna utilidad adicional a su efecto restaurador; por ejemplo, servir de cobijo y favorezca el restablecimiento de las poblaciones de elementos de la flora y fauna nativas, proporcionándoles un hábitat y alimento.

5. Baja tendencia a adquirir una propagación malezoi de invasora, incontrolable.

6. Presencia de nódulos fijadores de nitrógeno o micorrizas que compensen el bajo nivel de nitrógeno, fósforo y otros nutrientes en el suelo.

7. No ser comestibles por el hombre o por animales que pueden ser consumidos por éste.

La instalación de redes y conglomerados de vegetación apropiadamente escogida facilitada porla forma de lomadas contenedoras de residuos ayudaría a preservar la zona de erosión por viento, y a restaurar la biodiversidad local.

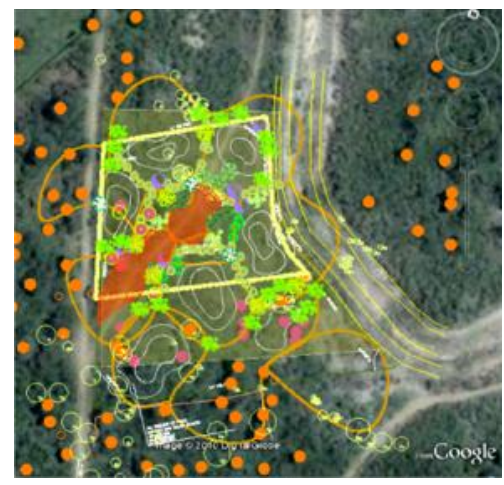

Fig. 8 Planteamiento final para la instalación de la vegetación nativa en el área clausurada del botadero Las Lomas.

\section{CONCLUSIONES}

El uso de la biodiversidad en el Perú para la recuperación paisajista de un área clausurada de botadero no ha sido investigado y los casos de aplicación han sido muy limitados, principalmente porque en Perú no se invierte en la clausura de los botaderos. Por lo que se hace necesaria la fitorremediación con especies nativas por su facilidad de adaptación y economía en su propagación y mantenimiento.

Las intervenciones de clausura realizadas con vegetación nativa no aseguran la continuidad del ecosistema y del paisaje que se quiere recuperar, es necesario un enfoque integral, iniciar el proceso de construcción de una red o sistema de conservación con una mayor cobertura, tomando las redes del macro paisaje.

El mantenimiento de la conectividad ecológica se realiza a partir de la implantación de una red verde que actúe como refugio de las especies silvestres, que conecte los distintos hábitats y diversifique el paisaje. La eficacia de este diseño dependerá de la mayor o menor conectividad alcanzada entre los distintos parches del paisaje.

En Las Lomas, la vegetación del bosque seco es un recurso que aúnes abundante y muy adecuado para la recuperación de áreas contaminadas por residuos sólidos, la gran profundidad que alcanzan las raíces de los árboles y arbustos, producto de su adaptación al desierto y a los ciclos del Fenómeno del Niño y de la Niña; permite que sobrevivan a la falta de agua, a las sustancias que pueden afectarlas, a la quema de residuos y los grandes periodos de sequía. Weberbauer ${ }^{[14]}$ reconoció a esta formación vegetal como "leñosas dispersas, siempre-verdes, mantenidas por el agua subterránea" con algunas especies caducifolias adicionales y presencia de algunas herbáceas. Esta descripción es la meta paisajista y de recuperación ambiental a alcanzar.

La fragmentación del paisaje es una de las principales causas de la pérdida de integridad del paisaje, por lo que las redes de conservación deben tender a minimizar sus efectos.

La conexión a través de las redes verdes permiten la permeabilidad del paisaje entre todos los elementos que lo conforman: los parches, su 
distribución espacial, los corredores discontinuos, así como las barreras existentes.

Los corredores existentes, por su ancho y estructura son parches alargados y delgados que dan a la estructura los "eco-tonos" apropiados a la restauración, los caminos poco transitados mantienen en sus bordes las condiciones homogéneas que permiten la existencia de determinados tipos de vegetación y pequeña fauna que se desplaza entre los parches.

Dos de los cruces de los parches-corredor, son muy favorables porque al cruzarse en "十" y uno en " $T$ ", permiten mejores movimientos y flujos a través del paisaje, tanto de la flora como de la fauna, en estos puntos se instala vegetación más compleja y proporciona en consecuencia, un hábitat más rico en especies.

El Paisaje del bosque seco de las Lomas está fragmentado por la actividad agrícola y algunos usos urbanos incipientes. $\mathrm{Su}$ grado de fragmentación es de $29.44 \%$, denominado Salpicado o Jaspeado, es decir, que ha perdido el hábitat, que no está correctamente conectado y tiene tendencia al efecto borde.

Se ha encontrado cinco parches; de los cuales el más difícil de recuperar por el grado de intervención que significa el contener al estadio local (parche A con 7.22\%). El parche más grande (B con $10.20 \%$ ) es un área dedicada a la actividad agrícola, la cual ya debe tener su propia dinámica interna, éste es un parche vecino al parche que contiene al botadero $\mathrm{E}(3.03 \%)$.

Sin embargo, el área Matriz presenta grandes posibilidades para su restauración ecológica paisajista porque el parche del botadero es relativamente pequeño, está al centro de los cuatro parches y esta cruzado por corredores naturales y artificiales estructuradores.

En la zona del botadero han sido eliminados el $100 \%$ de los árboles, por lo que se consideró densidad cero para el análisis y la evaluación paisajista. Con la restauración se estima alcanzar una densidad final de 50 árboles/ha, recomendada por el proyecto Algarrobo ${ }^{[14]}$.

La especie arbórea históricamente predominante en Piura ${ }^{[2,14,22]}$ y particularmente en la zona del botadero son los Algarrobos Prosopispallida (95\%), los árboles de Faique Acacia macracantha, los que complementan esta densidad arbórea, éstos últimos han sido plantados como límites de resguardo en los caminos y como seguridad entre las parcelas de cultivo.

La estructura de la distribución espacial de ambas especies de árboles, se asemeja a polígonos hexagonales, la que compondrá la red o tejido permeable de restauración propuesta, tal que se una a los corredores macro existentes interrumpidos por la actividad del botadero.

Esta forma hexagonal favorece la delimitación de los montículos de residuos, cuyas aristas constituirán las zanjas de coronación -para la captación de aguas de escorrentía-, a su vez las zanjas de coronación servirán para la instalación de vegetación, es decir, como corredores de restauración ecológica.

La vegetación arbórea colocada completó la estructura de la macro red de restauración, la vegetación arbustiva hizo lo mismo en los corredores-zanja de coronación, proporcionando el hábitat inicial para el retorno de la vida silvestre, se espera que la vegetación herbácea de diverso tipo, funcione como una bio-cobertura filtrando el agua de lluvia y protegiendo contra la erosión del suelo.

Las especies arbustivas de tamaño alto que abundan luego de la temporada de lluvia son el Overo Cordialutea, el cual crece asociado estrechamente a la Borrachera Ipomoea carnea, la Borrachera es mencionada por la literatura como símbolo de la deforestación y el avance de la actividad agrícola, pero en este caso se utilizará como especie pionera por su agresivo crecimiento en las condiciones difíciles del botadero.

Las semillas de herbáceas nativas contenidas en la tierra vegetal depositada sobre los residuos, al brotar naturalmente durante la temporada de lluvia, rellenarán el área sobre los montículos evitando la erosión del viento. Esta vegetación pionera probablemente acumule en su estructura los elementos tóxicos de los residuos, se requerirá hacer una evaluación de la bio-acumulación y de la eliminación de materia tóxica del suelo. 
Los árboles y arbustos al crecer reorganizarán visualmente el paisaje, los corredores estructurarán la circulación del agua, posibles lixiviados y de los nutrientes, el área recuperada se constituirá en un atractor para el retorno a corto plazo de la vida silvestre.

Posteriormente la vegetación pionera tanto de los bordes como la que cubra la superficie de los montículos o lomas, deberá ser retirada, evaluada y eliminada de manera segura -incinerada por su probable acumulación de sustancias tóxicas en los tejidos- para instalar nuevas plantas que continuarán con el proceso de recuperación ambiental del área clausurada.

Los bordes y corredores existentes se enriquecieron en esa dinámica al ser considerados como ejes base para el diseño de las redes de conservación más finas y detalladas a modo de un tejido que permeabilice la zona de bosque seco en la zona del botadero.

Como conclusión final, la restauración del área clausurada del botadero permitirá que el bosque seco complete su tejido macro, recomponiendo de esta forma su paisaje, a la vez que se aprovecha esta área como una Reserva y parque de conservación natural.

\section{AGRADECIMIENTOS}

Quiero expresar mi profunda gratitud a la Mag. Ing. Gladys Monge Talavera, por su incondicional apoyo, conocimientos, experiencia y guía en el camino a la recuperación del ambiente en un área poco desarrollada como es la disposición final de los residuos sólidos. A la Asociación Benéfica PRISMA por la inapreciable posibilidad de realizar mi investigación sobre sus trabajos en la recuperación de la salud ambiental en el distrito de las Lomas, al Ing. Carlos Aguilar en Lima, a los ingenieros Jorge Flores, Pedro Pingo y Nelson Aguilar en Piura; al Ing. Agro. Mario Matorel por sus valiosos conocimientos sobre la vegetación del bosque seco piurano. Agradezco por el apoyo financiero brindado a esta investigación al INIFAUA Instituto de Investigación de la Facultad de Arquitectura, Urbanismo y Artes, y al IGI Instituto General de Investigación de la UNI. Quiero mencionar al Arq. Miguel Muñoz y a la Arq. Maite Cervantes por sus aportes a la visión paisajista; y a todas aquellas personas que me tuvieron la suficiente paciencia en mis andanzas para interpretar este particular paisaje y ecosistema peruano. $\mathrm{Y}$ a todas aquellas personas que hicieron posible con sus habilidades tecnológicas el mostrar el futuro del Bosque Seco restaurado.

\section{REFERENCIAS}

1. España Junta de Andalucía "La fragmentación del paisaje como principal amenaza a la integridad del funcionamiento del territorio". España, La Comunitat Valenciana. Decreto 120. 2006 Reglamento de Paisaje.

2. Leal-Pinedo, J. M., "Los Bosques Secos de la Reserva de Biosfera del Noroeste (Perú): Diversidad Arbórea y Estado de Conservación Reserva de Biosfera del Noroeste, Instituto Nacional de Recursos Naturales, Tumbes, Perú”, 2005.

3. Morlans, M. C., "Introducción a la Ecología del paisaje y estructura del paisaje Editorial Científica Universitaria”, Universidad Nacional de Catamarca ISSN: 1852-3013, 2005.

4. Torres Guevara, F., "Minería Metálica bajo El NIÑO en Piura: Injustificado riesgo para su vida y desarrollo. Colectivo ciudadano "Piura Vida y Agro" Godofredo García Baca, Oxfam, Coordinadora Nacional de Derechos Humanos, Piura. 2003.

5. Vázquez Yanes, C., Batis Muñoz, A. I., Alcocer Silva, M. I., Gual Díaz, M, Sánchez, D, C., "Árboles y arbustos nativos potencialmente valiosos para la restauración ecológica y la reforestación", Proyecto J-084 - Conabio Instituto de Ecología, Universidad Nacional Autónoma de México. Apdo.Postal 70-275, Ciudad Universitaria, 04510 México D. F., México.

6. Espinace A., R., Palma G., J., Szanto, N. M., Olaeta, C. J. A. "Recuperación de áreas utilizadas como vertederos controlados de R.S.U. Experiencias y proposiciones. Universidad Católica de Valparaíso".

7. Félix Herrán, J. A., Sañudo Torres, R. R., Martínez Ruiz, R., Rojo Martínez, G. E., Olalde Portugal, V., "Biorremediación de Suelo, Agua y Aire, Desarrollo 
Sustentable Universidad Autónoma Indígena de México.

8. Jaramillo, J., "Guía para el Diseño, Construcción y Operación de Rellenos Sanitarios Manuales. OPS/CEPIS/PUB/02.93 Universidad de Antioquia, Colombia.

9. Olaeta, C., José, A., Espinace, A. R., Szantó, N. M., Palma, G. J., "Experiencias de Reinserción de vertederos mediante la implantación de una cubierta vegetal XII", Congreso Chileno de Ingeniería Sanitaria y Ambiental Copiapó, Chile. 1997.

10. Perú, Presidencia del Consejo de Ministros, "Reglamento para el Diseño, Operación y Mantenimiento de Infraestructuras de Disposición Final de Residuos Sólidos del Ámbito Municipal: Rellenos Sanitarios". 2008.

11. Wenche, E. D., Forman Richard T. T., Olson, J. "Landscape Ecology Principles in Landscape Architecture and Land-Use Planning GSD", President and fellows of Harvard College 1996.

12. Ferreyra, R., 1983 Los tipos de vegetación de la costa peruana. Anales del Jardín Botánico de Madrid 40(1):241-256.

13. Maestre, F. T., 2002. "Restauración de la cubierta vegetal en zonas semi áridas en función a los factores bióticos y abióticos". Tesis Doctoral. Universidad de Alicante. Obtenido de la Biblioteca virtual Miguel de Cervantes 30 de junio del 2010.

14. Perú, INRENA "Evaluación de la fenología del Prosopis en el departamento de Lambayeque Chiclayo: Proyecto Algarrobo". Ministerio de Agricultura; Lima, Embajada Real de los Países Bajos, 2003 Sistematización realizada por: Ing. Juan Alarcón Díaz

15. Weberbauer, A., "Clima y vegetación en los Andes del Perú y en su territorio costanero", discurso de inicio de ciclo Academia de Ciencias Exactas. 1944.

16. Perú, INRENA Instituto Nacional de Recursos Naturales. "Mapa de bosques secos del departamento de Piura Memoria descriptiva”. INR-82-DGEP. Lima-Perú. 1998.

17. Linares Palomino, R., La Torre M. de los A., "Mapas y clasificación de vegetación en ecosistemas estacionales: un análisis cuantitativo de los bosques secos de Piura", Rev. Perú. biol. 15(1): 31-42 (2008) Facultad de Ciencias Biológicas UNMSM Versión on line ISSN 1727-9933.

18. USA EnvironmentalProtection Agency EPA http://www.epa.gov/espanol

19. Barrera-Cataño, J. I., Valdés-López, C., "Herramientas Para Abordar La Restauración Ecológica De Áreas Disturbadas En Colombia”. UniversitasScientiarum. Revista de la Facultad de Ciencias Edición especial II, Vol. 12, 11-24 Pontificia Universidad Javeriana. Colombia. 2007.

20. Vasquez, P., Burneo, F., Canziani, E., Ríos, J., "Las Plantas silvestres en la alimentación del venado cola blanca coto de caza El Angolo Piura, guía de campo para su reconocimiento". Centro de datos para la Conservación UNALM, Lima. 2007.

21. Jaramillo, J., "Guía para el Diseño, Construcción y Operación de Rellenos Sanitarios Manuales". OPS/CEPIS/PUB/02.93 Universidad de Antioquia, Colombia. 2002.

22. Linares Palomino, R. "Diversidad y endemismo de plantas leñosas de bosques tropicales estacionalmente secos del Perú", obtenido el 8 de setiembre del 2010 de www.unal.edu.co/icn/publicaciones/caldasi a.htm.

Correspondencia: aisaje_urbano@yahoo.es 